\title{
Study of rheological and mechanical properties of ternary blends of iPP/LDPE/EPDM
}

\author{
Said Bouhelal ${ }^{1,2}$, M. Esperanza Cagiao ${ }^{3}$, \\ Maria Laura Di Lorenzo ${ }^{4}$, Foued Zouai ${ }^{1,2}$, \\ Souhila Khellaf ${ }^{1,2}$, Habiba Tabet ${ }^{1,2}$, \\ Djafer Benachour ${ }^{1,2}$ and Francisco J. Baltá Calleja ${ }^{3, *}$ \\ ${ }^{1}$ LMPMP, Faculty of Technology, Ferhat Abbas University, \\ Sétif, Algeria \\ ${ }^{2}$ Unité de Recherche Matériaux Emergents, Ferhat Abbas \\ University, Sétif, Algeria \\ ${ }^{3}$ Instituto de Estructura de la Materia, Macromolecular \\ Physics, CSIC, Serrano 119, 28006 Madrid, Spain, \\ e-mail: embalta@iem.cfmac.csic.es \\ ${ }^{4}$ Istituto di Chimica e Tecnologia dei Polimeri, CNR, Via \\ Campi Flegrei, 34, c/o Comprensorio Olivetti, edificio 70, \\ 80078 Pozzuoli (NA), Italy \\ * Corresponding author
}

\begin{abstract}
Compatible blends of isotactic polypropylene (iPP)/lowdensity polyethylene (LDPE)/ethylene-propylene-diene monomer (EPDM) were prepared by reactive blending in the presence of dicumyl peroxide (DCP). The blends were characterized using different techniques: dynamical rheological analysis (DRA), differential scanning calorimetry (DSC), optical microscopy (OM) and scanning electron microscopy (SEM), dynamical mechanical thermal analysis (DMTA), viscosity and impact strength, to evaluate their properties. Results revealed that the presence of the peroxide in LDPE/ EPDM blends gives rise to crosslinking reactions, as is the case in iPP/LDPE/EPDM blends. However, in the latter case, scission reactions of the iPP component also take place. As a consequence of the whole process, morphological changes arise mainly in the amorphous regions, without affecting the degree of crystallinity of the components. The mechanical properties of the blends are consequently improved, due to the crosslinked network thus formed in the blends.
\end{abstract}

Keywords: mechanical properties; reactive blending; rheology; ternary blends.

\section{Introduction}

Blending of thermoplastic polymers is an effective way to obtain final products with new and special combinations of properties [1-3]. Polyolefins, such as polyethylene (PE) and isotactic polypropylene (iPP), with growing ratios of $2 \%$ and $6 \%$ per year, respectively, represent a large amount of the produced and consumed thermoplastic materials nowadays. Several articles devoted to the study of characteristics shown by blends of different types of PE [4], or PP/PE blends [5-7], have been reported. However, PE and iPP, as most thermoplastic polymers, are immiscible with each other. To overcome this problem of immiscibility, and to obtain products with improved characteristics, compatibilizer materials should be added to the blends [8]. Compatibilizers are usually classified as non-reactive (random, graft and block copolymers, varying in nature, which should have polarities similar to the blend component), and reactive [8]. Ethylene-propylene-diene monomer (EPDM) copolymers are classified as non-reactive compatibilizers, and as such, have been widely used with the iPP/PE systems [9, 10]. Nevertheless, reactive blendings of iPP, PE and EPDM can be obtained in the presence of a peroxide as the radicals' source [11]. Within this context, a study dealing with the reversible crosslinking of iPP/low-density polyethylene (LDPE) blends, prepared by reactive extrusion in the presence of a peroxide, has been recently reported [12].

The peroxide induces radical reactions involving three steps: a) cleavage of the peroxide; b) formation of macroradicals; and c) combination of different macroradicals with chain termination. The final polymer blend will either be a graft, block or random copolymer, or will have an interpenetrating network structure. In any case, the structure and morphology of the blend components are modified, thus affecting the mechanical properties of the resulting materials [1-3]. In preceding articles, we reported the microhardness study of ternary blends of polyolefins, recycled or freshly prepared [13], and also, of binary or ternary blends of polyolefins and polyamide 66 [14]. The preparation of such complex blends demands well understood and properly predicted reactive mechanisms. Hence, a firm control of the processing conditions is required in order to optimize the final properties of the blends. A homogenous and fine dispersion of EPDM in iPP/PE blends leads to advantageous crosslinking, which stabilizes the phase structure of the blend, preventing the demixing during further processing operations or industrial applications.

The aim of the present study is to examine blends of LDPE and iPP, compatibilized with EPDM, in the presence of a peroxide (DCP). The combination of different characterization techniques allowed us to correlate rheological, mechanical, thermal and morphological properties of these blends.

\section{Experimental}

\subsection{Materials}

The materials used in this investigation were the following: LDPE: B21 sak, supplied by ENIP, Skikda, Algeria; iPP: 
Sabic-Vestolen 9000-67404, supplied by Chemische Werke Hüls, Ruhr, Germany; EPDM: Mordel 2744, hexadiene type, supplied by DuPont de Nemours, Wilmington, Delaware, USA; Peroxide: DCP-40, Vanderbilt Co Inc., Norwalk, Connecticut, USA (mixed with $40 \%$ of phthalate).

\subsection{Blend preparation}

Firstly, the blend components were mixed in the solid state, using a small quantity of vegetable oil, in order to wet and improve the dispersion of the fine powder of peroxide within the granules of LDPE, iPP and EPDM. Thereafter, the mixture was introduced into a single screw extruder. The extrusion cycle was repeated twice in order to achieve a homogeneous blend. Injection and compression molding machines were finally used to prepare samples for the different tests.

\subsection{Techniques}

2.3.1. Dynamical rheological analysis (DRA) For the dynamic rheological analysis, a Brabender-type plastograph was used. The study of the torque variation (torque $=$ moment of force) as a function of time, reports the rheological behavior of different iPP/LDPE/EPDM reactive blends in the presence of peroxide. Figure 1 illustrates the different steps of the torque-time evolution for a crosslinked polyolefin material. From this figure, it can be seen that initially, the polymer melts and the torque decreases to a minimum value, which describes the transformation from the solid to the molten state (point $\mathrm{T}_{\mathrm{A}}$ ). As the crosslinking reaction begins, the torque increases until it reaches the maximum value $T_{B}$ (point $B$ ). After that, a partial decrease of the torque is observed. This slight decrease is attributed to the partial destruction of the network formed. Then, a leveling off takes place with an almost constant torque $\mathrm{T}_{\mathrm{C}}$ value at the point $\mathrm{C}$, usually higher than $T_{A}$. The $T_{C}$ value depends on the content and efficiency of the crosslinking agents.

The analysis of the torque-time evolution exhibited by ternary blends based on iPP/LDPE matrix and reactive EPDM in the presence of aggressive oxy-radicals, reveals complex

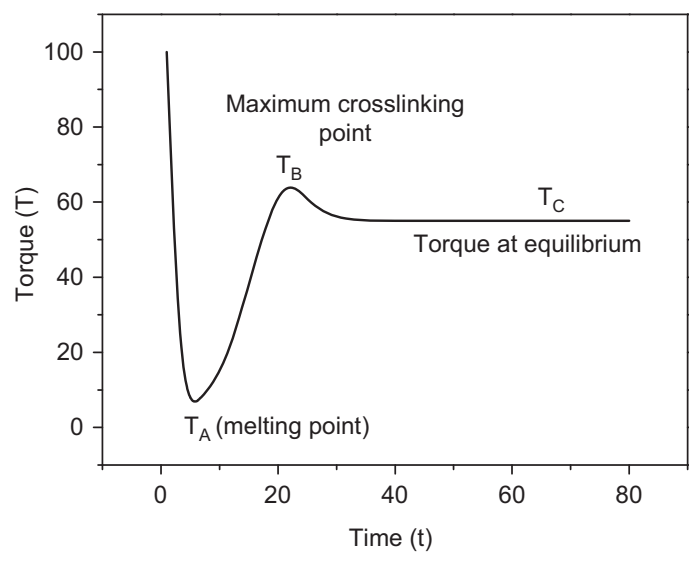

Figure 1 Torque-time evolution for a crosslinked polyolefin material. crosslinking reactions involving the different components [11]. These reactions occur simultaneously in the molten state. This approach is used to assess the contribution of each component (iPP, LDPE and EPDM), and the way in which it reacts with the others. The co-rotating speed chosen can detect the viscosity change of the blend melt flow.

The torque-time rheometer was used for each component separately, as well as for binary and ternary blends. Using the method developed by Harpell and Walrod [15], i.e., plotting the logarithm of the velocity constant $k$ as function of $1 / T$, we found that the crosslinking reaction kinetics follows an Arrhenius law type variation. In the case of the ternary blends, the crosslinking reaction is very complex. The kinetics of this reaction will be significantly influenced by the presence of the different components, i.e., iPP, LDPE, EPDM, and the peroxide. The resulting structure of these ternary blends could be considered rather as that of an interpenetrating network (IPN).

2.3.2. Differential scanning calorimetry (DSC) The calorimetric study was performed in a Mettler Toledo Star System 30 equipment. Sample weight was between 10 and $15 \mathrm{mg}$.

Two methods were used in order to determine the fusion enthalpy $\left(\Delta \mathrm{H}_{\mathrm{m}}\right)$, the melting temperature $\left(\mathrm{T}_{\mathrm{m}}\right)$ and the crystallization temperature $\left(\mathrm{T}_{\mathrm{c}}\right)$ of the blends.

According to the first method, the samples were firstly heated from $-120^{\circ} \mathrm{C}$ up to $200^{\circ} \mathrm{C}$ (heating rate $=10^{\circ} \mathrm{C} / \mathrm{min}$ ), maintained at $200^{\circ} \mathrm{C}$ for $10 \mathrm{~min}$, and then cooled down from $200^{\circ} \mathrm{C}$ to $-120^{\circ} \mathrm{C}$ (cooling rate $=-50^{\circ} \mathrm{C} / \mathrm{min}$ ). A second heating run was performed with the same conditions as the first one.

In the second method, samples were heated from $25^{\circ} \mathrm{C}$ up to $200^{\circ} \mathrm{C}$ (heating rate $=20^{\circ} \mathrm{C} / \mathrm{min}$ ), and then cooled down from $200^{\circ} \mathrm{C}$ to $25^{\circ} \mathrm{C}$ (cooling rate $\left.=-10^{\circ} \mathrm{C} / \mathrm{min}\right)$.

The degree of crystallinity was calculated using the theoretical melting enthalpy values for $100 \%$ crystalline polymers: for $100 \%$ crystalline $\mathrm{PE}, \Delta \mathrm{H}_{\mathrm{m}}=293.86 \mathrm{~J} / \mathrm{g}$ and for $100 \%$ crystalline iPP, $\Delta \mathrm{H}_{\mathrm{m}}=207.33 \mathrm{~J} / \mathrm{g}$ were used [16].

2.3.3. Optical microscopy (OM) Optical microscopy $(\mathrm{OM})$ was employed using an Olympus apparatus equipped with a hot stage and photography accessories connected to a computer. Specimens were cut from compression molded sheets and squeezed between two glass slides, to obtain very thin films. The specimens were heated from room temperature up to $200^{\circ} \mathrm{C}$ at a rate of $20^{\circ} \mathrm{C} / \mathrm{min}$, then kept at that temperature for $10 \mathrm{~min}$, to ensure uniform melting, and finally cooled down to room temperature at a rate of $-10^{\circ} \mathrm{C} / \mathrm{min}$.

2.3.4. Scanning electron microscopy (SEM) The scanning electron microscopy (SEM) analysis was performed using a Philips 501 equipment. Specimens were cut from compression molded sheets, and samples of $1 \mathrm{~mm}$ thickness were immerged and fractured in liquid nitrogen before being metalized. The fractured surface must not be taught, in order to ensure its correct metallization. This process was carried out at a high rotational speed, in order to fix the golden powder. Following this, the samples were ready for SEM analysis. 
2.3.5. Impact strength test The impact strength test was carried out using a device equipped with a temperature control unit varying from $-20^{\circ} \mathrm{C}$ to room temperature. Specimens were prepared by compression molding. Notched (1/3 deep) and unnotched specimens were submitted to Izod strength testing: impact strength $\mathrm{a}_{\mathrm{n}}$ (unnotched) and $\mathrm{a}_{\mathrm{k}}$ (notched) values, and $\mathrm{K}$ values were calculated using a hammer of 4 Joules. Measurements were carried out at $-15^{\circ} \mathrm{C}$ and at room temperature, according to the ISO $190 \mathrm{R}$ norm.

2.3.6. Steady state capillary rheometer The apparatus was a Prolabo capillary rheometer, with the following characteristics:

length/diameter ratio: $\mathrm{L} / \mathrm{D}=30$; cylinder diameter $=10 \mathrm{~mm}$; die diameter $=1 \mathrm{~mm}$.

The apparent and corrected viscosities were measured according to the power law model, applying the Rabinowitch correction to obtain the viscosity values. The die had a conical feeding shape and a flat exit shape. The processing temperature was $200^{\circ} \mathrm{C}$.

\subsubsection{Dynamical mechanical thermal analysis}

(DMTA) The tangent $\delta$, the logarithm of the real modulus $E^{\prime}$ and the glass transition temperature $\left(\mathrm{T}_{\mathrm{g}}\right)$ of the blends were measured using a DMTA apparatus (Rheometric Scientific MK III). Data were recorded in the tensile mode from $-150^{\circ} \mathrm{C}$ to $200^{\circ} \mathrm{C}$ using a scanning rate of $5^{\circ} \mathrm{C} / \mathrm{min}$ and a frequency of $3 \mathrm{~Hz}$.

\section{Results and discussion}

\subsection{Blends}

3.1.1. Binary blends The experimental results of the torque-time evolution at $200^{\circ} \mathrm{C}$ for the iPP/EPDM blend show that the torque decreases with time, being even lower in the presence of peroxide (see Figure 2). This is due to the attack by the peroxide radicals (particularly at the tertiary

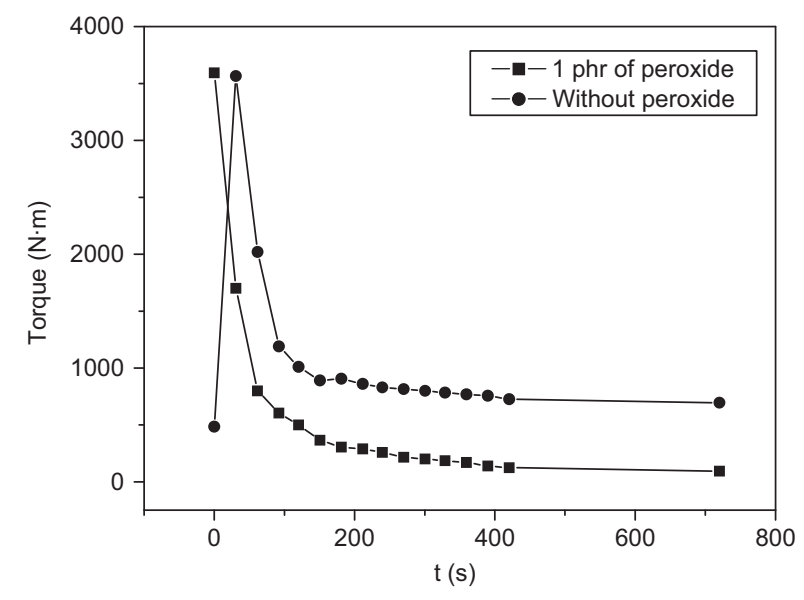

Figure 2 Comparison of the torque as a function of time for blends based on iPP/20 phr of EPDM in presence of peroxide and without peroxide at $200^{\circ} \mathrm{C}$. carbons of iPP, which are the more reactive sites), to form macroradicals by disproportionation or by cyclization of the end groups. The higher the peroxide concentration $\left(\mathrm{P}_{\text {conc }}\right)$, the lower was the torque value; this is attributed mainly to the fact that iPP degradation, in the presence of peroxide, results in shorter chains through scission reactions. This means that the viscosity will diminish, owing to the decrease in the $\mathrm{M}_{\mathrm{w}}$. Such a result has been already reported by Braun et al. on an iPP+peroxide system, in the absence of EPDM [17]. To effectively crosslink the iPP in the presence of a peroxide, it is necessary to use a coagent, i.e., a furan or bismaleimide based one [18]. Moreover, a new method, which allows the reversible crosslinking of the iPP, has been recently developed [19].

On the contrary, in other studies based on LDPE in the presence of peroxide, but without EPDM, an increase in the torque value was observed. This was an indication that crosslinking reactions occurred [20], originating a molecular weight $\mathrm{M}_{\mathrm{w}}$ increase. In fact, by using para-xylene as a solvent instead of dissolution, as is the case for iPP, swelling was observed in the case of LDPE.

The experimental results concerning the LDPE/EPDM system at $180^{\circ} \mathrm{C}$ (Figure 3), show an increase of torque until a maximum value $T_{B}$ is reached. This is followed by a gradual decrease up to a leveling off value $\mathrm{T}_{\mathrm{C}}$ (reached after approx. $940 \mathrm{~s}$ ). Torque equilibrium will take place at a much longer processing time. From the experimental results, it is seen that the $T_{B}$ and $T_{C}$ values increase with peroxide content. At the same time, the difference $\left[T_{B}-T_{A}\right]$ becomes higher. As $P_{\text {conc }}$ increases, the propagation rate rises as well. Therefore, a larger number of crosslinks will be formed at shorter times. This fast crosslinking reaction will give rise to a higher degree of crosslinking. In this case, the overall developed network will be more difficult to destroy.

From the results shown in Figures 2 and 3, it can be concluded that the peroxide radicals activate the unsaturated double bonds of EPDM. In addition, it is found that with LDPE, the peroxide acts in a similar way and forms LDPE

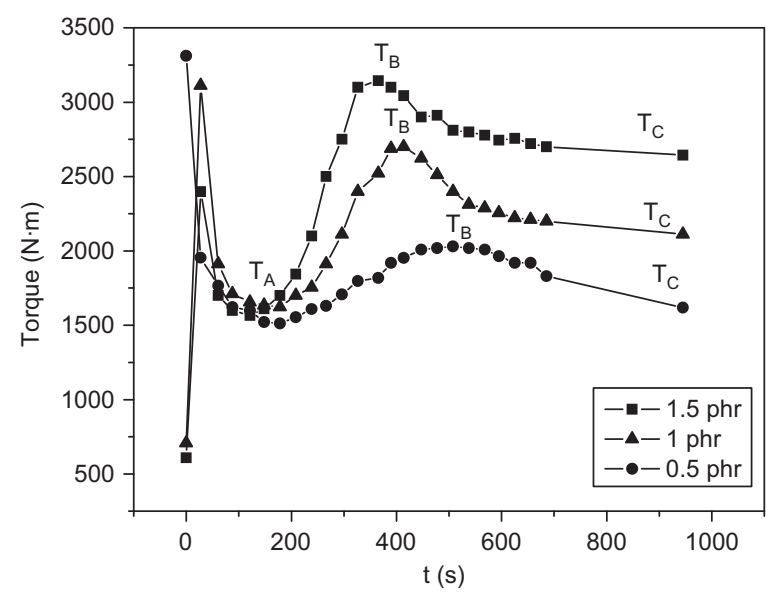

Figure 3 Variation of the torque as a function of time for the blend (LDPE/EPDM) with different peroxide contents at $180^{\circ} \mathrm{C}$. 
macroradicals by abstraction of hydrogen $\mathrm{H}$ atoms from secondary or primary carbon atoms, due to the high branching degree of LDPE. According to the crosslinking speed represented by the $\left[\mathrm{t}_{\mathrm{B}}-\mathrm{t}_{\mathrm{A}}\right]$ value, or by calculation of the reaction constant using the Monsanto method, the results indicate that, as $\mathrm{P}_{\text {conc }}$ increases, the rate of termination is faster. This result is also observed in the case of EPDM in the presence of peroxide. As mentioned above, the torque-time evolution of binary blends of LDPE/EPDM (Figure 3) shows that, both, $\mathrm{T}_{\mathrm{B}}$ and $\mathrm{T}_{\mathrm{C}}$ increase to higher values with the peroxide content. This could be due to the junction points of the networks (derived from LDPE macromolecules), the unsaturated double bonds of EPDM and/or the combination of LDPE and EPDM ethylenic macroradicals.

Moreover, from the DMTA analysis, the blend LDPE/ EPDM with the composition 100/20 (see Figure 4) shows the formation of a propylenic contribution (with a small maximum appearing at $\approx-10^{\circ} \mathrm{C}$, i.e., the $\mathrm{T}_{\mathrm{g}}$ of $\mathrm{iPP}$ ) even if iPP is not used. This is due to the $\beta$-scission of the propylenic part of EPDM. These propylenic chains have a low $\mathrm{M}_{\mathrm{w}}$ according to the ethylenic/propylenic ratio in EPDM. This propylenic contribution interferes in the torque value acting as a lubricant. The amount of PP formed depends on the $\mathrm{P}_{\text {conc }}$ and on the $\mathrm{M}_{\mathrm{w}}$ of iPP content in EPDM, due to the fact that the propylenic chains present a lower $\mathrm{M}_{\mathrm{w}}$ and, consequently, more fluidity. At this stage, the torque value does not correspond to the crosslinking involved. The values of $\mathrm{T}_{\mathrm{B}}$ and $\mathrm{T}_{\mathrm{C}}$ are also closely dependent on the ethylenic/propylenic ratio, rather than on the terpolymer efficiency. This is because there is a competition between crosslinking on one side and scission on the other, thus, a compromise value of the torque is reached, and such a value is an expression, not only of the crosslinking extent, but also of the scission degradation level. One should take into account the effect of each contribution of the EPDM's composition. The torque-time behavior and the $T_{B}$ and $T_{C}$ values are very useful in predicting the effect on $M_{w}$ qualitatively. There is no direct way to evaluate, either the $M_{w}$ of iPP, or its amount, since the three blend components are soluble in ortho-, para-, and metha-xylene solvents.

The experimental results obtained on the DRA study of iPP/EPDM in the presence of peroxide, show that there is no

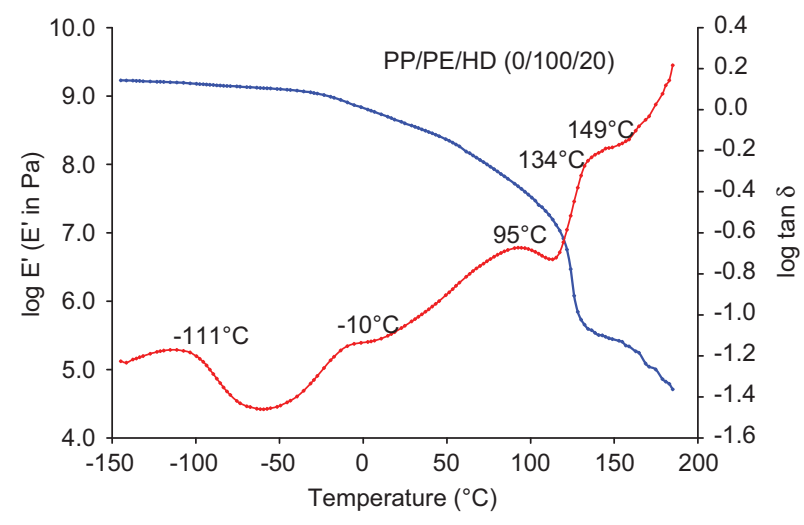

Figure 4 DMTA analysis of the blend iPP/LDPE/EPDM with the composition 0/100/20. maximum, i.e., the $T_{B}$ point does not appear (Figure 2). This is mainly due to the high amount of iPP with low $\mathrm{M}_{w}$ generated by the $\beta$-scission of iPP and by the propylenic part of EPDM. A rapid solubility test using para-xylene, shows that there is a partial swelling of the blends, mainly due to the reaction of the unsaturated double bonds of hexadiene present in EPDM, and also, to the crosslinking of the ethylenic part of EPDM. Here, it should be mentioned that the anti-oxidant or anti-ozone additives usually added can inhibit the peroxide attack. It is also clear that modified iPP copolymers will react in a different way as iPP homopolymers. In any case, the overall results show that it is preferable that the blend of iPP/ EPDM is used without peroxide.

3.1.2. Ternary blends Figure 5 illustrates the torquetime evolution at $200^{\circ} \mathrm{C}$ for ternary blends iPP/LDPE/20 phr EPDM, having a different LDPE content and a constant peroxide concentration of $0.5 \mathrm{wt} \%$. The evaluation of $\mathrm{T}_{\mathrm{B}}$ and $\mathrm{T}_{\mathrm{C}}$ at the equilibrium shows that the crosslinking effect starts to be apparent from (50/50) of iPP/LDPE matrix composition and the torque increases when LDPE content is predominant. This positive deviation is proportional to the degree of crosslinking of LDPE and EPDM. As mentioned previously, the formation of a complex network takes place, and the evolution of the torque is affected by the iPP degradation (through $\beta$-scission reaction). However, this degradation has no apparent effect on the crosslinking reaction.

\subsection{DSC analysis}

The melting enthalpy $\Delta \mathrm{H}_{\mathrm{m}}$ and the melting temperature $\mathrm{T}_{\mathrm{m}}$ of each component, and the total degree of crystallinity, derived by the first method, are reported in Table 1 for the different blends. The DSC analysis carried out for different compositions of iPP/LDPE with $20 \mathrm{phr}$ of EPDM, shows that the $\mathrm{T}_{\mathrm{m}}$ of LDPE and iPP are almost the same as the characteristic ones for the raw materials; the variation does not exceed $4^{\circ} \mathrm{C}$.

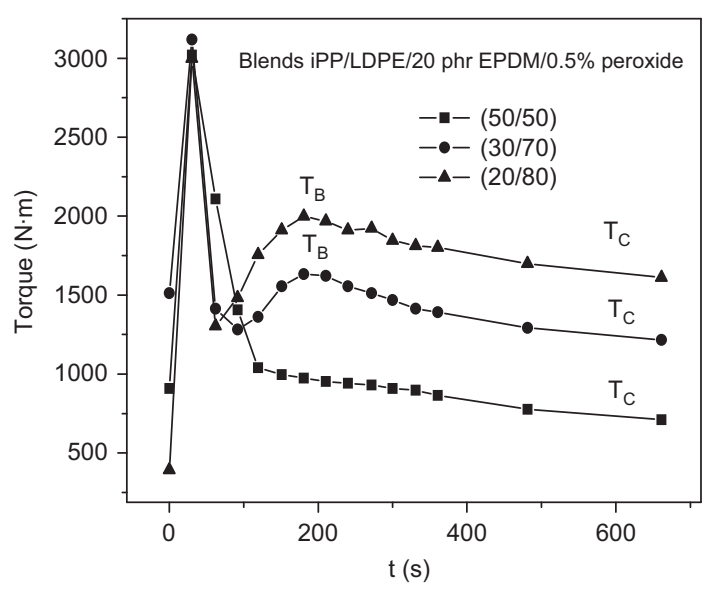

Figure 5 Variation of the torque as a function of time for different blends based on (iPP/LDPE) with $20 \mathrm{phr}$ of EPDM and $0.5 \mathrm{wt} \%$ of peroxide at $200^{\circ} \mathrm{C}$. 
Table 1 Melting temperatures and melting enthalpies obtained for different blends based on iPP/LDPE/20 phr EPDM.

\begin{tabular}{lccccc}
\hline Blend composition: iPP/LDPE+20 phr EPDM & $\mathrm{T}_{\mathrm{m}}{ }^{1}\left({ }^{\circ} \mathrm{C}\right)$ & $\mathrm{T}_{\mathrm{m}}{ }^{2}\left({ }^{\circ} \mathrm{C}\right)$ & $\Delta \mathrm{H}_{\mathrm{m}}{ }^{1}(\mathrm{~J} / \mathrm{g})$ & $\Delta \mathrm{H}_{\mathrm{m}}{ }^{2}(\mathrm{~J} / \mathrm{g})$ & $\mathrm{Crystallinity}(\%)$ \\
\hline 100/0+EPDM & 113 & 165 & 6 & 44 & 23 \\
80/20+EPDM & 111 & 167 & 9 & 47 & 26 \\
50/50+EPDM & 110 & 166 & 28 & 25 & 22 \\
20/80+EPDM & 112 & 164 & 51 & 15 & 24 \\
0/100+EPDM & 114 & 166 & 46 & 15 & 23 \\
EPDM & 53 & - & 23 & - & - \\
\hline
\end{tabular}

From Table 1, one also sees that the sample with the matrix composition iPP/LDPE 20/80 shows the highest $\Delta \mathrm{H}_{\mathrm{m}}$ value $\left(\Delta \mathrm{H}_{\mathrm{m}}=\Delta \mathrm{H}_{\mathrm{m}}{ }^{1}+\Delta \mathrm{H}_{\mathrm{m}}{ }^{2}\right)$. The enthalpy of fusion of each peak is a function of the iPP or LDPE content in the matrix. The crystallization temperatures $\mathrm{T}_{c}$, obtained for the different blends by using the second method, are shown in Table 2. In addition, according to the $T_{c}$, there is an effect on the mode of crystallization of each crystalline part. This is due to the fact that when iPP starts to crystallize, LDPE is still in the molten state, and this will affect the nucleation rate of the iPP. On the other hand, when LDPE starts to crystallize, the iPP is in a solid state and this will then affect the growing rate of LDPE. Therefore, we end up with smaller spherulites. As a result, the two modes are related to the chain dispersion. In addition to that, the EPDM improves close contact in the interphase confined space, resulting in a decrease of the interfacial tension. Another point has to be mentioned: the network effect through the crosslinking degree. Thus, some of the macroradical portions, either of iPP or of $\mathrm{PE}$, could form covalent bonds and will be part of one type of network. Therefore, this complex situation will strongly affect the overall crystallization phases, either the enthalpies of crystallization or the $\mathrm{T}_{\mathrm{c}}$. In the thermogram of the blend iPP/LDPE/EPDM 50/50/20 (see Figure 6), one observes the appearance of a new peak at $\mathrm{T}=123^{\circ} \mathrm{C}$, which corresponds to the HDPE characteristic melting peak. This peak appears only in the first run, and is

Table 2 Temperatures of crystallization obtained for different blends based on iPP/LDPE/20 phr EPDM.

\begin{tabular}{lcrrrr}
\hline Blend composition: iPP/LDPE+20 phr EPDM & $100 / 0$ & $80 / 20$ & $50 / 50$ & $20 / 80$ & $0 / 100$ \\
\hline $\mathrm{T}_{\mathrm{c}}^{1}\left({ }^{\circ} \mathrm{C}\right)$ & 110 & 108 & 100 & 92 & 92 \\
$\mathrm{~T}_{\mathrm{c}}^{2}\left({ }^{\circ} \mathrm{C}\right)$ & 95 & 92 & 92 & 80 & 78 \\
\hline
\end{tabular}

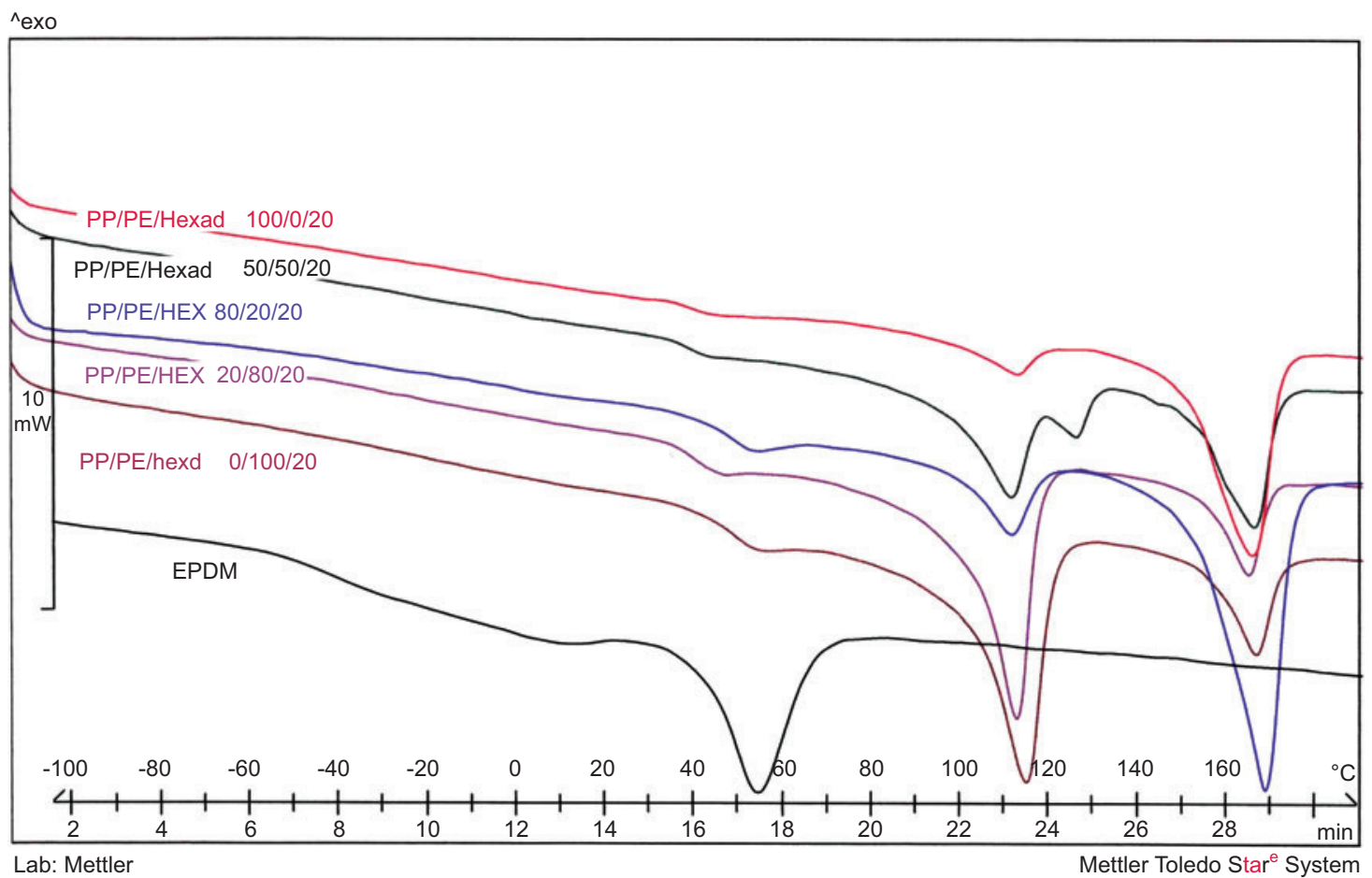

Figure 6 Melting curves of the different reactive blends based on (iPP/LDPE) with $20 \mathrm{phr}$ of EPDM included in this study. 
thought to be due to the shear effect involved even in a plasticorder, or in an extruder. In the melt, blends undergo high shear. Then, the melt fracture of the side chains or branching chains of LDPE will result in regular chains, capable of crystallizing differently, as compared to the raw material. This result could be related to the presence of oxyradicals and macroradicals of ethylenic chains, coming from both EPDM and polyethylene present in the ternary blends.

\subsection{Optical microscopy and SEM analysis}

Optical microscopy observations (see micrographs in Figure 7) illustrate the dependence of the spherulite size on the blend composition. The dimensions are larger for pure iPP and diminish as LDPE content increases, or when the EPDM is used. The iPP spherulite sizes are much larger than the LDPE ones. Therefore, in the blends, the iPP spherulite dimensions will depend on the blend composition. This result should, in turn, affect the overall or the sum of the two crystallinity degrees of the $\mathrm{PP}$ and $\mathrm{PE}$, thus inducing a change in the mechanical properties [21]. However, the total crystallinity of the blends remains practically constant (see Table 1).

The influence of blend composition can be noticed on the micrographs of the different blends (see Figure 8). For blends containing either iPP or LDPE, and EPDM, rough fractured surfaces are observed (Figure 8A and E). This is also the case for the ternary blend iPP/LDPE/EPDM 50/50 (Figure 8C). When the fraction of either iPP or LDPE is the largest one, a smooth surface is observed, suggesting the predominance of ductile fracture as opposed to brittle fracture (Figure 8B and D).

In addition, LDPE and EPDM crosslinking in the presence of peroxide form a complex network; this could be accompanied by further induced crystallization of crystallizable materials within and between spherulites. Based on optical microscopy and SEM results for 80/20/20 EPDM and 20/80/20 EPDM blends (Figure 8B and D), and on the corresponding impact strength results (Figure 9A and B), it was observed that, as the spherulite radius decreases, the fracture surface becomes more apparent. On the other hand, for the 50/50/20 EPDM blend (Figure 8C), the networks formed and further crystalline parts induce rougher fracture surfaces with brittle regions. As a result, it may be concluded that there is a competition between the formation of crystalline regions and crosslinked zones, due to the presence of EPDM, and, in particular, of the double bonds of the diene monomer forming the crosslinked network.

\subsection{Impact resistance properties}

Figure 9 shows the variation of the impact strength as a function of the LDPE content for notched and unnotched iPP/LDPE/20 phr EPDM specimens, at two different temperatures: at room temperature (Figure 9A), and around $-15^{\circ} \mathrm{C}$, i.e., close to the $T_{g}$ of iPP (Figure 9B). In these figures, $a_{n}$ represents the impact strength value for the unnotched specimens, whereas $a_{k}$ is the impact strength value for the notched ones. We used this approach to examine the influence of EPDM on the impact strength.

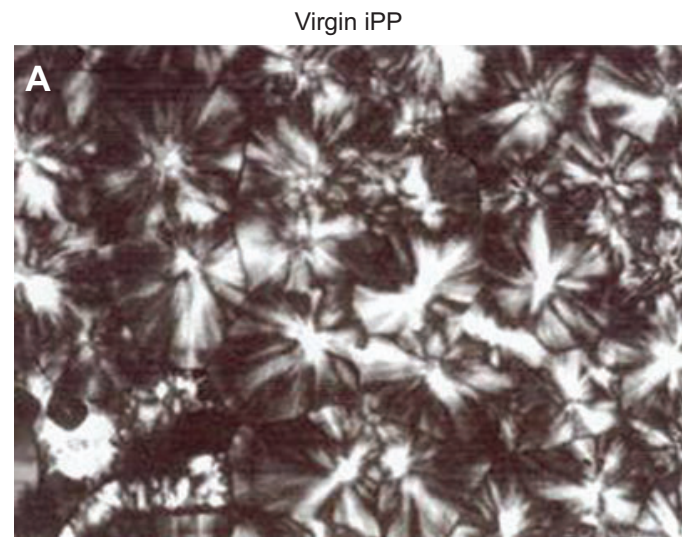

iPP/LDPE/EPDM 100/0/20

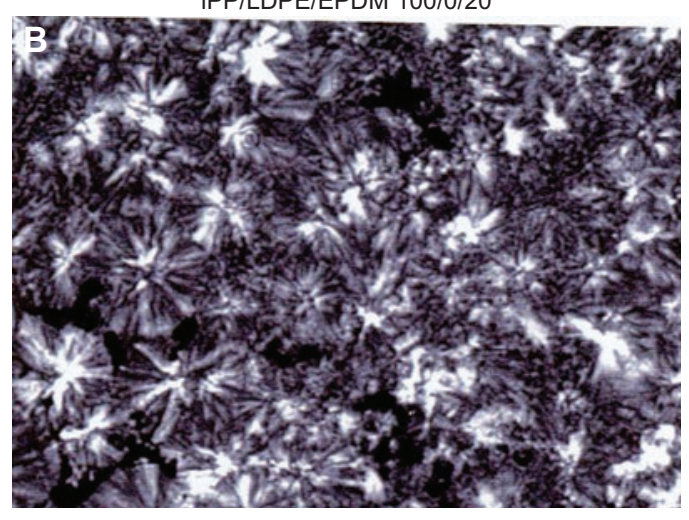

iPP/LDPE/EPDM 50/50/20

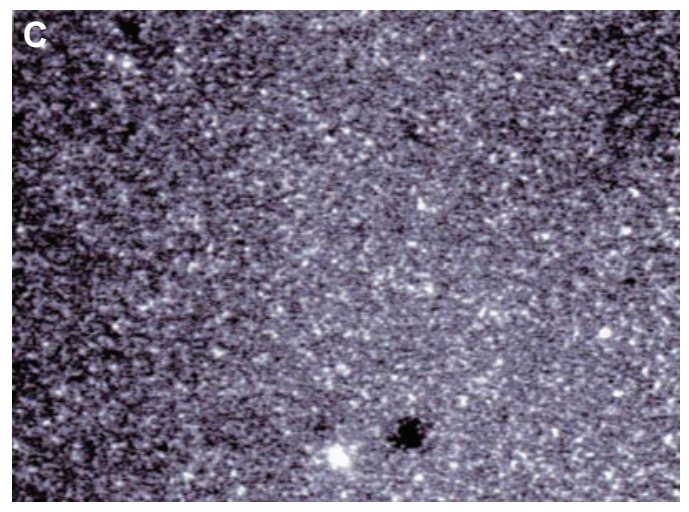

iPP/LDPE/EPDM 0/100/20

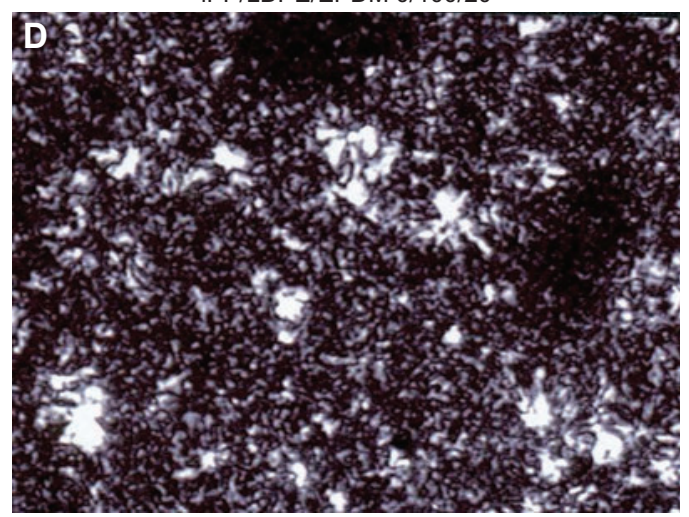

Figure 7 Optical micrographs of different blends based on iPP/ LDPE with $20 \mathrm{phr}$ EPDM in the presence of $0.5 \mathrm{wt} \%$ of peroxide under crossed polarizers (300x). 

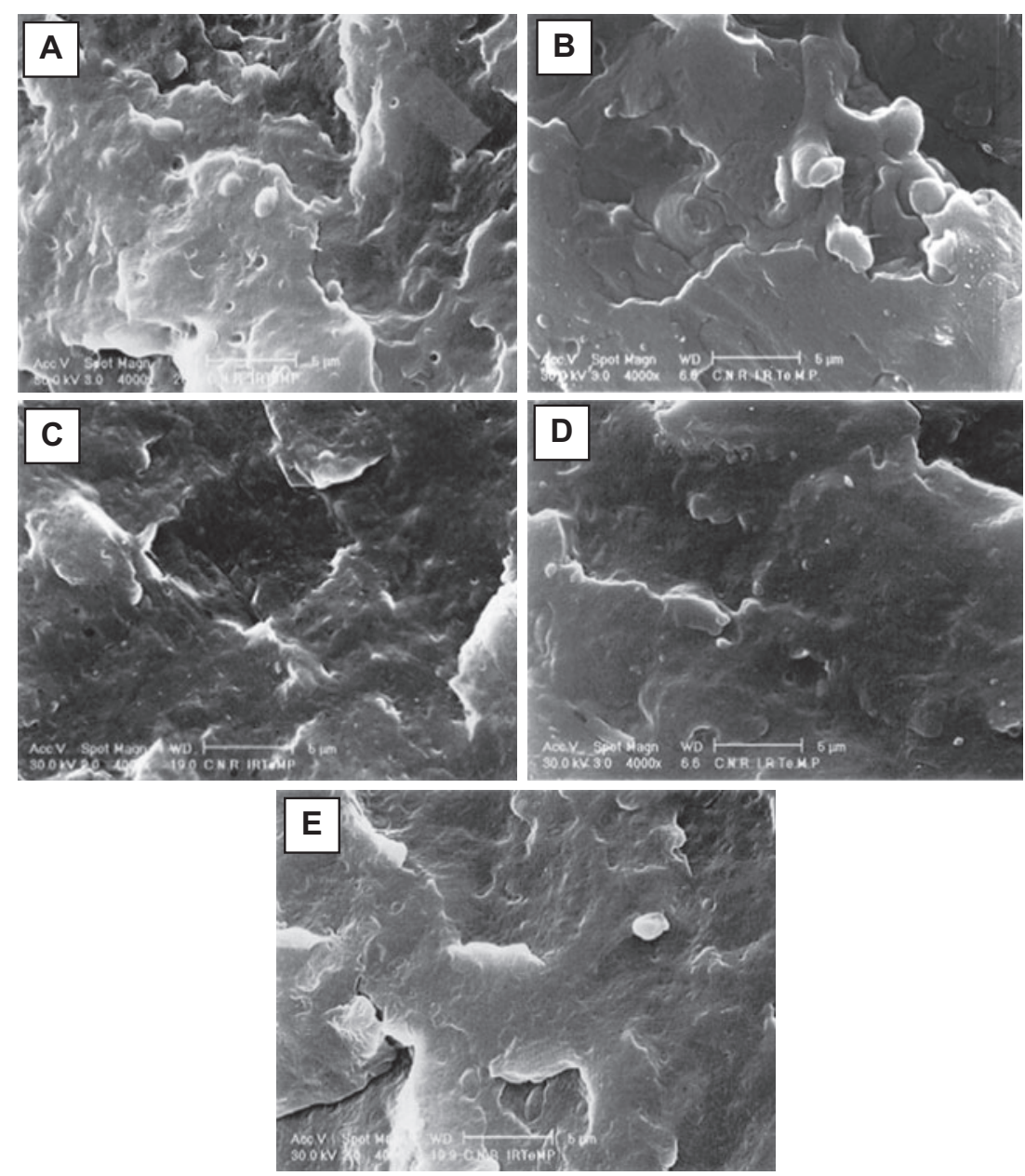

Figure 8 SEM micrographs of brittle fractured surfaces of different reactive blends based on (iPP/LDPE) with 20 phr EPDM: (A) 100/0; (B) 80/20; (C) 50/50; (D) 20/80; (E) 0/100 (4000x).

The impact strength variation (with LDPE content) of the unnotched samples does not follow a "regular" path as the one observed for the notched samples. This difference can be explained as follows: in the notched samples, an initiation to the propagation step to fracture is induced by the notch, whereas this is not the case for the unnotched ones. In addition, Figure 9 also illustrates that the impact strength depends strongly on the sample preparation process [22].

The effect of LDPE content on $a_{k}$ is apparent for concentrations above $50 \%$. The curves show relatively low values of $a_{n}$ and $\mathrm{a}_{\mathrm{k}}$, notably for LDPE content values below $50 \%$. At room temperature (Figure 9A), the critical proportion 50/50 of iPP/ LDPE matrix shows a synergistic effect for $a_{n}$. In addition, (Figure 9A), a brittle/ductile transition for $\mathrm{a}_{\mathrm{k}}$ from low values $\left(\approx 3-4 \mathrm{~kJ} / \mathrm{m}^{2}\right)$ to quite high values $\left(\approx 30-33 \mathrm{~kJ} / \mathrm{m}^{2}\right)$ is observed for the blends with $50-70 \%$ of LDPE. This is due to the different modifications which the blend had undergone. The influence of EPDM and reactive blending to form a network, has a direct effect on impact fracture. The mode of dispersion of the different components, and the network architectural structure, are positive factors to get more relaxed blends with less residual stresses. As it is known, the EPDM decreases the interfacial tensions due to its ethylenic chains. The LDPE and EPDM increase the impact strength due to the chains high mobility. In summary, the above results indicate a semi-brittle fracture type for the blends with high proportion of iPP and a brittle-ductile fracture transition at around $60-70 \%$ of LDPE content; the ductile behavior takes place for higher LDPE contents due to a strong interfacial adhesion and high crosslinking degree. This can also be attributed to the simple fact that LDPE exhibits more ductility and, consequently, is more impact resistant than iPP.

\subsection{Steady state capillary rheometry}

The results obtained with a capillary rheometer, at a constant shear strain of $100 \mathrm{~s}^{-1}$ (see Figure 10) indicate that the EPDM content does not affect the viscosity when the LDPE concentration $\leq 50 \%$. When the LDPE concentration $>50 \%$, EPDM contents $>15$ phr will result in a decrease of the viscosity of the blend. The increase in viscosity as a function of the LDPE amount is evident from the 50/50 composition onwards, and becomes higher as the LDPE proportion predominates. This result is also observed in the DRA testing; 

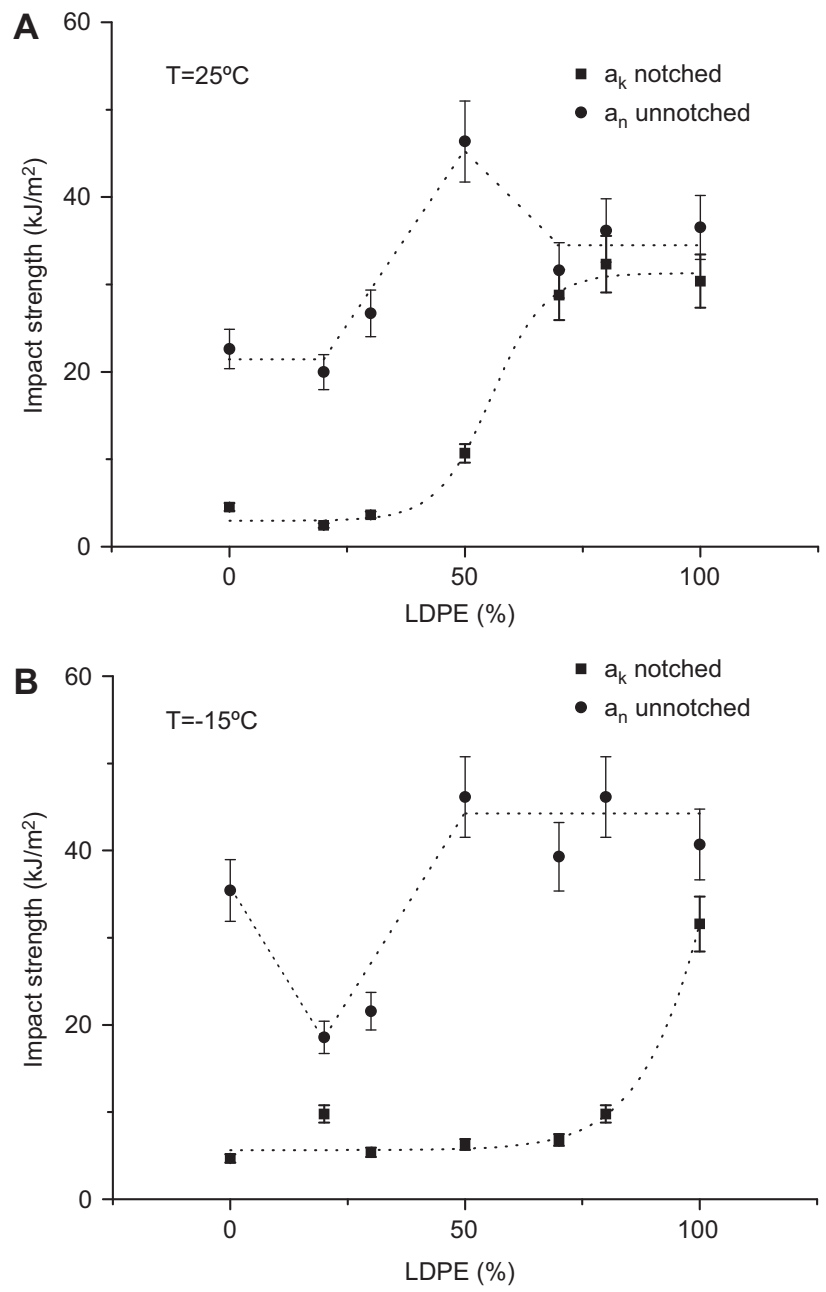

Figure 9 Variation of the impact strength as a function of the LDPE content for iPP/LDPE/20 phr EPDM blends: (A) at room temperature and (B) at $-15^{\circ} \mathrm{C}$.

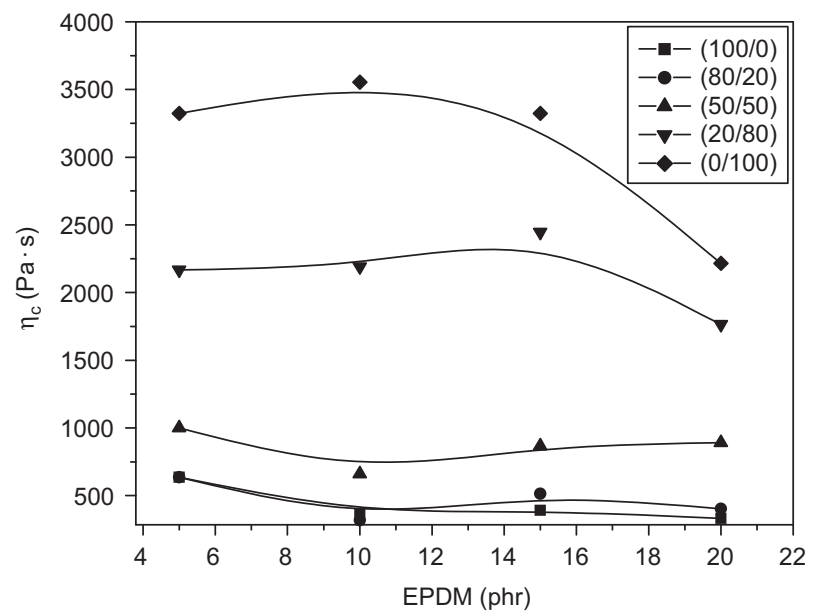

Figure 10 Variation of the corrected viscosity as a function of EPDM phr for different blends based on (iPP/LDPE) matrix at a constant shear strain $\left(100 \mathrm{~s}^{-1}\right)$. the steady state viscosity shows a good correlation with the torque values at equilibrium $\mathrm{T}_{\mathrm{C}}$. This could be written as follows: $\mathrm{T}_{\mathrm{C}}=\mathrm{K} \eta$. The increasing viscosity describes an increase of networks being formed. It can be concluded that, when the macroradicals are formed, only a part of them contribute to the network formation. The macroradicals efficiency is closely dependent on different parameters (i.e., processing conditions and peroxide nature). Therefore, network formation is a complex phenomenon, resulting in a viscosity increase.

\subsection{DMTA results}

The results of the DMTA analysis for the composition iPP/ LDPE/EPDM (0/100/20) (Figure 4), indicate the presence of a $\mathrm{T}_{\mathrm{g}}$ at $\approx-10^{\circ} \mathrm{C}$, corresponding to the $\mathrm{T}_{\mathrm{g}}$ value of iPP, no matter whether iPP is added or not. This is due to the $\beta$-scission of the propylenic part of EPDM in the presence of peroxide, which gives rise to the iPP chains. This low $M_{w}$ iPP will act as an external lubricant due to repulsive intermolecular forces. In addition, the different diagrams allow us to distinguish between some differences in the characteristic peaks. This could be explained by the fact that the chains are more relaxed for the (50/50/20) iPP/ LDPE/EPDM composition, as compared to the binary blends. This is mainly due to the EPDM effect and the free volume generated by the complex interpenetrating networks formed.

Figure 11 shows the variation of the viscoelastic modulus $\mathrm{E}^{\prime \prime}$ for different blend compositions, tested at four different temperatures $\left(22,-16,-60\right.$ and $\left.-100^{\circ} \mathrm{C}\right)$. It is noted that, from the corresponding plots, the $\mathrm{E}^{\prime \prime}$ value of the neat composition based on iPP/EPDM (100/20), taken at $22^{\circ} \mathrm{C}$, is very close to that of the ternary blend iPP/LDPE/EPDM (50/50/20), taken at $-16^{\circ} \mathrm{C}$. This result illustrates the fact that the reactive blending forms a complex structure, while improving the structure stability of incompatible components such as iPP and LDPE.

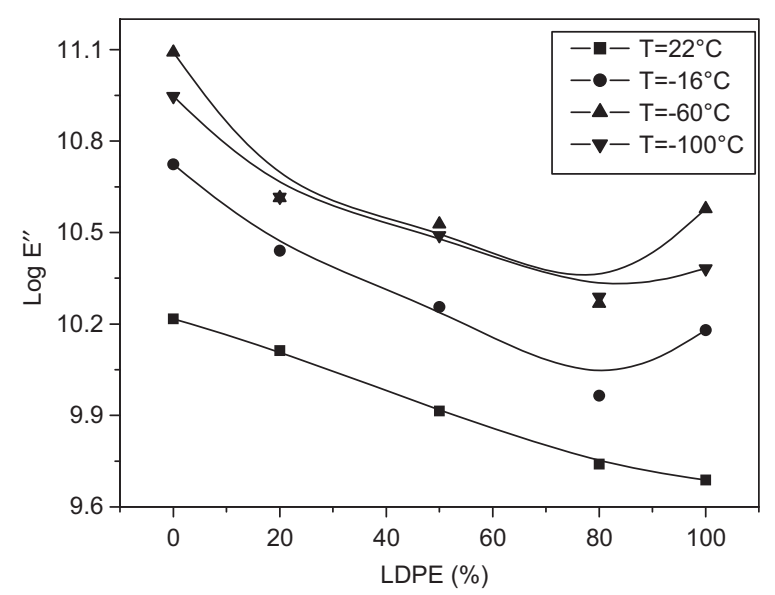

Figure 11 Variation of viscoelastic modulus E" (in Pa units) as a function of blend composition for iPP/LDPE/20 phr EPDM blends at different testing temperatures. 


\section{Conclusions}

From the above results, it can be concluded that the blends prepared through the reactive blending behave in a different way to the traditional ones:

(a) DRA results show that binary blends based on LDPE/ EPDM present complex crosslinked reactions; at least, there are two separate crosslinking reactions added to the inter-reaction between the two reactive components.

(b) The ternary blends (iPP/LDPE/EPDM) present complex crosslinking reactions, accompanied with a scission reaction of the iPP. The overall final structure is closely dependant on the peroxide type and concentration, the weight content of the crosslinkable components (LDPE and EPDM) and the iPP scission reaction. These morphological changes occur mainly in the amorphous regions, only slightly affecting the crystalline regions.

(c) In addition, there is a weight ratio (mass) effect on the thermal properties and the viscoelastic modulus of the blends. Thus, some characteristics, such as $\mathrm{T}_{\mathrm{c}}$ of the blend components, are modified.

(d) The spherulite size reduction does not obey the traditional theory, and the mechanical properties of the blends are improved. It may be suggested that there is a compensatory effect of the decrease in the spherulite size by the new final structure (crosslinked network) due to the reactive effect.

(e) Summarizing, the novel blends based on iPP/LDPE/ EPDM appear as useful materials, both, from the mechanical and viscoelastic point of view.

\section{Acknowledgements}

FJBC and MEC gratefully acknowledge the MICINN, Spain (Grants FIS2010-18069 and MAT2009-07789, respectively), for the generous support of this investigation. SB and MEC thank the financial support of the AECID (Agencia Española de Cooperación Internacional para el Desarrollo) (Grant C/032183/10).

\section{References}

[1] Robeson, LM. Polymer Blends: A Comprehensive Review, Carl Hanser Verlag: Munich, 2007.

[2] Paul, DR, Bucknall, CB, Eds. Polymer Blends. Volumes I and II. John Wiley \& Sons: New York, USA, 1999.

[3] Deanin, RD, Manion, MA. In Polymer Blends and Alloys. Shonaike, GO, Simon, GP, Eds., Marcel Dekker: New York, 1999, Chapter 1, p. 1.

[4] Hosoda S, Gotoh Y. Polym. J. 1988, 20, 17-30.

[5] Kim BK, Do IH. J. Appl. Polym. Sci. 1996, 60, 2207-2218.

[6] Lovinger BJ, Williams ML. J. Appl. Polym. Sci. 1980, 25, 1703-1713.

[7] Blom HP, Teh JW, Rudin A. J. Appl. Polym. Sci. 1995, 58, 995-1006.

[8] Datta, S, Lohse, DJ. Polymeric Compatibilizers. Hanser Gardner Publications: Munich, Germany, 1996.

[9] Hemmati M, Nazokdast H, Shariat Panahi H. J. Appl. Polym. Sci. 2001, 82, 1138-1146.

[10] Kim BK, Kim MS, Kim KJ. J. Appl. Polym. Sci. 1993, 48, 1271-1278.

[11] Kim BK, Choi CH. J. Appl. Polym. Sci. 1996, 60, 2199-2206.

[12] Bouhelal S, Cagiao ME, Khellaf S, Benachour D, Baltá Calleja FJ. J. Appl. Polym. Sci. 2008, 109, 795-804.

[13] Berdjane K, Berdjane Z, Rueda DR, Benachour D, Baltá Calleja FJ. J. Appl. Polym. Sci. 2003, 89, 2046-2050.

[14] Krache R, Benachour D, Cagiao ME, Baltá Calleja FJ, Bayer RK, Tschöpe F. Int. J. Polymer. Mat. 2003, 59, 939-956.

[15] Harpell, GA, Walrod, DH. In Plastics Additives Handbook, 4th ed., Gachter, R, Muller, H, Klemchuk, PP, Eds., Hanser: Munich, 1993, Chapter 17.

[16] Wunderlich, B. Macromolecular Phys. Vol. 3: Crystal Melting, Academic Press: New York, 1980, p. 48.

[17] Braun D, Richter S, Hellmann GP, Ratzsch M. J. Appl. Polym. Sci. 1998, 68, 2019-2028.

[18] Romani F, Corrieri R, Braga V, Ciardelli F. Polymer 2002, 43, $1115-1131$.

[19] Bouhelal S, Cagiao ME, Benachour D, Baltá Calleja FJ. J. Appl. Polym. Sci. 2007, 103, 2968-2976.

[20] Kunert KA, Soszynska H, Pislewski N. Polymer 1981, 22, 1355-1360.

[21] Way JL, Atkinson JR, Nutting J. J. Mater. Sci. 1974, 9, 293-299.

[22] Kang GB, Kim MH, Son Y, Park OO. J. Appl. Polym. Sci. 2009, $111,3121-3127$. 